\title{
(6) OPEN ACCESS \\ Ten tips for advancing a culture of improvement in primary care
}

\author{
Tara Kiran, 1,2,3,4 Noor Ramji, ${ }^{1,2}$ Mary Beth Derocher, ${ }^{1,2}$ Rajesh Girdhari, ${ }^{1,2}$ \\ Samantha Davie, ${ }^{1}$ Margarita Lam-Antoniades ${ }^{1,2}$
}

\begin{abstract}
${ }^{1}$ Department of Family and Community Medicine, St Michael's Hospital, Toronto, Ontario, Canada ${ }^{2}$ Department of Family and Community Medicine, University of Toronto, Toronto, Ontario, Canada

${ }^{3}$ Centre for Urban Health Solutions, St. Michael's Hospital, Toronto, Ontario, Canada ${ }^{4}$ Health Quality Ontario, Toronto, Ontario, Canada
\end{abstract}

\section{Correspondence to} Dr Tara Kiran, Deptartement of Family and Community Medicine, St. Michael's Hospital, Toronto, ON M5B 1W8, Canada; tara.kiran@utoronto.ca

Received 12 June 2018 Revised 10 September 2018 Accepted 14 October 2018 Published Online First 31 October 2018

\section{Check for updates}

(c) Author(s) (or their employer(s)) 2019. Re-use permitted under CC BY-NC. No commercial re-use. See rights and permissions. Published by BMJ.

To cite: Kiran T, Ramji N,

Derocher MB, et al.

BMJ Qual Saf

2019;28:582-587.

\begin{abstract}
Embracing practice-based quality improvement (QI) represents one way for clinicians to improve the care they provide to patients while also improving their own professional satisfaction. But engaging in care redesign is challenging for clinicians. In this article, we describe our experience over the last 7 years transforming the care delivered in our large primary care practice. We reflect on our journey and offer 10 tips to healthcare leaders seeking to advance a culture of improvement. Our organisation has developed a cadre of QI leaders, tracks a range of performance measures and has demonstrated sustained improvements in important areas of patient care. Success has required deep engagement with both patients and clinicians, a long-term vision, and requisite patience.
\end{abstract}

The quality of primary care in both Canada and the USA consistently ranks poorly compared with other high-income countries on a variety of performance measures. For example, patients in the USA and Canada are less likely to report getting a timely appointment when sick, or easily accessing care on the weekend or holidays from their primary care practitioner. ${ }^{1}$

At the same time, there are increasing levels of burn-out and job dissatisfaction among physicians. Some of these feelings relate to frustrations with electronic medical records and increases in non-clinical clerical work. More fundamentally, the way we provide primary care today often makes it difficult for physicians to engage in personal, caring relationships with patients. ${ }^{2}$

Embracing practice-based quality improvement (QI) is one way for clinicians to improve the care they provide to patients while also improving their own professional satisfaction. ${ }^{3}$ But engaging in care redesign is challenging for clinicians. Primary care professionals in North America are trained to provide excellent care to the patient in front of them. Few have been trained to measure and improve the care they provide to a population of patients. Fewer still are familiar with improvement science or QI tools such as the Institute for Healthcare Improvement's Model for Improvement and the plan-do-study-act cycles.

In this commentary, we describe our experience over the last 7 years transforming the care delivered in our large primary care practice. We reflect on our journey and offer 10 tips to healthcare leaders seeking to advance a culture of improvement and clinician-led QI. Some of these tips were apparent to us at the start, while others come from insights we have developed through experiential learning.

\section{OUR JOURNEY}

In 2010, our practice transitioned to a Family Health Team, a medical home model that includes non-physician health professionals. ${ }^{4} 5$ We adopted an electronic medical record and transitioned to blended capitation payments for physicians in 2011. The same year, we strengthened our focus on QI. Our family health team now serves over 44000 enrolled patients at six clinical sites in a diverse urban area. ${ }^{6}$ The team includes approximately 170 healthcare professionals, including more than 70 staff physicians, approximately 38 resident physicians, and over 60 non-physician health professionals including nurses, social workers, dietitians and pharmacists. We have a 20-member interprofessional Quality Steering Committee that reviews data and helps set organisational priorities. Each site also has its own QI team to support local improvement and spread of organisational initiatives.

We have demonstrated sustained improvements in common problem areas in primary care such after-hours access and cancer screening (figure 1). We have an internal dashboard of quality indicators that we track over time (table 1). Indicators represent five of the six quality domains described by the Institute of Medicine and are derived from a variety 

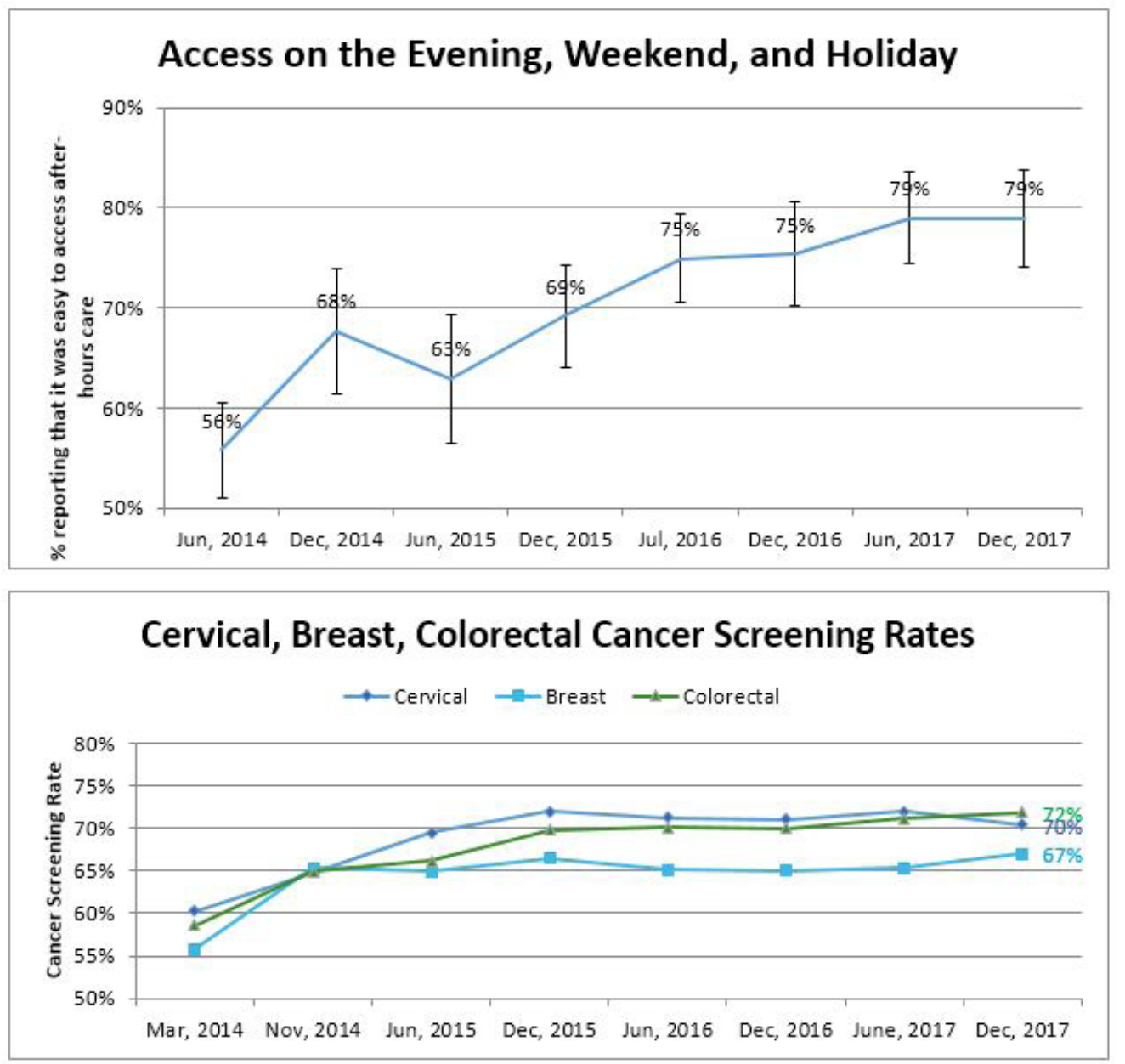

Figure 1 Progress on select dashboard measures as of December 31, 2017. (A) Each time point includes data from all respondents to the patient experience survey in the previous 6 months. Denominators: 190 (June 2014), 542 (December 2014), 213 (June 2015), 315 (December 2015 ), 375 (July 2016), 264 (December 2016), 309 (June 2017) and 266 (December 2017). (B) Each time point represents the percentage of patients up to date for screening among all enrolled patients eligible for screening. The denominator of eligible enrolled patients has increased over time due to the opening of a sixth clinic site in July 2015. December 2017 rates represent the proportion of eligible patients up to date or who declined screening. Cervical denominators: 12402 (March 2014), 12545 (November 2014), 12624 (June 2015), 12945 (December 2015), 13793 (June 2016), 13622 (December 2016$), 13$ 945 (June 2017) and 14387 (December 2017). Breast denominators: 4407 (March 2014), 4811 (November 2014), 4735 (June 2015 ), 5048 (December 2015), 5282 (June 2016), 5316 (December 2016), 5307 (June 2017) and 5599 (December 2017). Colorectal denominators: 9240 (March 2014 ), 10 201 (November 2014), 10165 (June 2015), 10733 (December 2015), 11280 (June 2016), 11255 (December 2016), 11426 (June 2017 ) and 11900 (December 2017).

of data sources, including manual chart audit, patient experience survey and our electronic medical record. Anecdotally, clinicians feel proud of our improvements and inspired to be involved in practice transformation efforts. We are learning from our successes and failures and offer the following tips to advance local QI.

\section{TEN TIPS FOR ADVANCING A CULTURE OF IMPROVEMENT IN PRIMARY CARE}

\section{Commit the time and resources}

Strengthening our focus on QI meant ensuring that a core set of physicians and other staff were paid to engage in improvement work. Our physician partnership agreed to redistribute clinical income to pay for a physician quality lead at each clinic. We used clinical income to supplement dedicated government funds to hire a full-time QI analyst to support data collection and reporting. Local QI teams, which comprised a physician, nurse, clerical and other interested staff, were supported to meet every 2 weeks. We provided QI training to all QI team members and have incorporated ongoing professional development into our monthly Quality Steering Committee meetings. We achieved buy-in by articulating a clear vision for a QI programme that responded to a number of external drivers, including increased accountability to government for quality and a direction from our affiliated university to teach QI. Staff physicians now run a 
Table 1 Quality improvement indicators for the St. Michael's Hospital Academic Family Health Team

\begin{tabular}{|c|c|c|}
\hline Quality domain & Measure & Source \\
\hline \multirow[t]{3}{*}{ Timely access } & $\begin{array}{l}\text { Percentage of patients reporting they saw a doctor, nurse practitioner or nurse the same or } \\
\text { next day when sick and needing care. }\end{array}$ & Patient experience survey \\
\hline & $\begin{array}{l}\text { Percentage of patients reporting that it was very easy or somewhat easy to get care from the } \\
\text { family health team when they needed medical care on an evening, weekend or holiday. }\end{array}$ & Patient experience survey \\
\hline & $\begin{array}{l}\text { Percentage of patients reporting that they always or often see or speak to the doctor or nurse } \\
\text { practitioner that they prefer. }\end{array}$ & Patient experience survey \\
\hline \multirow[t]{4}{*}{ Patient-centredness } & $\begin{array}{l}\text { Percentage of patients reporting that their doctor or nurse practitioner always or often gives } \\
\text { them an opportunity to ask questions about recommended treatment. }\end{array}$ & Patient experience survey \\
\hline & $\begin{array}{l}\text { Percentage of patients reporting that their doctor or nurse practitioner always or often spends } \\
\text { enough time with them. }\end{array}$ & Patient experience survey \\
\hline & $\begin{array}{l}\text { Percentage of patients reporting that their doctor or nurse practitioner always or often involves } \\
\text { them as much as they want to be in decisions about their care. }\end{array}$ & Patient experience survey \\
\hline & Progress on patient recommendations. & Organisation operations \\
\hline \multirow[t]{10}{*}{ Effectiveness } & Chronic disease prevention & \\
\hline & $\begin{array}{l}\text { Percentage of eligible patients up to date with (1) cervical, (2) breast and (3)colorectal cancer } \\
\text { screening. }\end{array}$ & EMR and provincial registry \\
\hline & Percentage of current smokers advised to quit in the last year. & EMR \\
\hline & Chronic disease management & \\
\hline & Percentage of patients with diabetes retained in care. & EMR \\
\hline & Percentage of patients with diabetes whose last blood pressure was less than $145 / 85$. & EMR \\
\hline & Percentage of patients with HIV retained in care. & EMR \\
\hline & Percentage of patients with HIV who have an undetectable viral load. & EMR \\
\hline & Transitions in care & \\
\hline & $\begin{array}{l}\text { Percentage of patients discharged home from the hospital's general internal medicine service } \\
\text { contacted by a fFamily Health tTeam clinician within } 7 \text { days. }\end{array}$ & Manual data collection \\
\hline \multirow[t]{4}{*}{ Safety } & Percentage of patients coprescribed an opioid and benzodiazepine. & EMR \\
\hline & $\begin{array}{l}\text { Percentage of patients prescribed an opioid medication (not including methadone or } \\
\text { buprenorphine-naloxone). }\end{array}$ & EMR \\
\hline & Percentage of patients age 65 and above prescribed a benzodiazepine. & EMR \\
\hline & Number of incident analyses resulting in operational changes. & Organisational operations \\
\hline Equity & $\begin{array}{l}\text { Screening rates for (1) cervical, ( } 2 \text { ) breast and ( } 3 \text { ) colorectal cancer for patients living in the } \\
\text { lowest neighbourhood income quintile divided by the screening rates for patients living in the } \\
\text { highest neighbourhood income quintile. }\end{array}$ & EMR and provincial registry \\
\hline
\end{tabular}

EMR, electronic medical record.

QI curriculum for residents, and residents contribute significantly to improvement work that is aligned with practice priorities.

\section{Appeal to intrinsic motivation}

Our QI efforts leveraged the intrinsic motivation of staff to improve patient care and education for learners. Many healthcare providers perceive QI as synonymous with governmental mandates and cost-cutting. We have been clear from the start that our QI priorities have been selected because staff and patients in our organisation think they are important. Our QI plan does include government-selected priorities (eg, timely access), but also incorporates relatively unique areas reflective of our practice setting (eg, HIV management). Our mandate to teach QI takes advantage of our clinicians' passion for teaching and motivates clinicians to develop related expertise. For example, we recently introduced safety incident reviews into the residency curriculum with the twin goals of increasing both staff and resident competency in the area.

\section{Measure and improve patient experience}

Our patient experience survey has been one of the most important drivers of QI in our organisation. We have developed and implemented a low-cost, feasible approach to collecting practice-level patient feedback using a regularly administered survey emailed to patients in their birth month. ${ }^{7}$ The response rate is about $20 \%$. In our setting, survey data have been easier to collect and analyse than data from our practice electronic medical record. Patient feedback has helped us identify and prioritise improvement opportunities (eg, awareness of our urgent care clinics). Unexpectedly, it has also helped us engage staff. Positive patient feedback has been rewarding for staff, and some patient recommendations have validated concerns staff had raised (eg, long waits on the phone). We also include two open-ended questions in the survey, which provide us with stories that complement data we present in graphs-these stories are more compelling to some staff than numbers. 


\section{Try and pick an early win}

We invested early efforts in improving cancer screening rates. This priority made sense for a number of reasons: our screening rates for cervical, breast and colorectal cancer were at or below the provincial average, there was evidence about what practice-based interventions lead to improvement, we had a core group of individuals with related interest and expertise, and our efforts aligned with existing physician financial incentives. Over a 6-month period, we focused efforts on developing a system for obtaining accurate data and proactively recalling patients overdue for cervical, breast or colorectal cancer screening. ${ }^{8}$ We have continued to make changes to our process to improve screening rates, understand and reduce inequities, and reduce costs. 9 Our early success demonstrated to staff that improvement was possible.

\section{Learn and adjust course when things don't go as planned}

Our very first initiative involved measuring and improving influenza immunisation uptake among patients 65 and older. We thought it would be a quick win. It was relatively easy to measure, it aligned with existing physician financial incentives, and we thought recalling patients proactively would be a relatively low-effort way of improving rates. We were disappointed when we saw little improvement in our numbers. In hindsight, we suspect we underestimated the impact of imperfect data. We could attribute immunisations documented in our practice electronic medical record but did not have data on immunisations given at public health units, specialists' offices or pharmacies. In Ontario, the last option has become an increasingly convenient and common source for patients to receive their immunisations. By 2014, the Quality Steering Committee felt it no longer made sense for us to spend our limited resources to supplement mass media campaigns and encourage patients to receive influenza shots at our clinic, so we dropped the measure from our QI plan.

\section{Try, try and try again}

Recognising failures is important, but some priorities-like timely access-are too important to give up on. In 2012, we began transparently reporting 'third next available' appointment data ${ }^{10}$ for all staff physicians on clinic desktop computers. Staff physicians had been receiving their own data confidentiality for over a year, and physicians on the QI committee felt unanimously that transparency was fair and could spur improvement. Most physicians were supportive but some felt unfairly targeted. We offered individualised support, organised local educational sessions and enrolled some teams in provincially run learning collaboratives. But we seemed to make little progress improving. More worryingly, physicians and staff seemed to be growing resentful and sceptical of QI. We decided to take a break from active improvement. We continued to monitor our performance and eventually renewed our efforts with new approaches. We began measuring access through our patient experience survey. We started measuring continuity, recognising it as an important balance to timely access. We used 'positive deviance ${ }^{11}$ to build on strengths: we interviewed physicians with a low 'third next available' appointment to identify strategies for improving access and shared these with colleagues through mentorship and written tip sheets. We became more explicit about the entire team's role in improving access. Most recently, we have held patient focus groups to better understand what access means to them. Recent data suggest a modest improvement in patient-reported access when sick.

\section{Involve patients in the improvement work}

Some of our biggest successes have happened because we involved patients in the improvement work. In 2014, only 56\% of our patients surveyed reported that it was easy to access care from our team on the evenings, weekends and holidays-despite us having urgent care clinics most evenings and on both weekend days, as well as a 24-hour telephone on-call service. We used principles of experience-based design ${ }^{12}$ to have patients help us understand the problem (low awareness of our urgent care options) and codesign solutions (email advertisement and reformatted waiting room posters). Now close to $80 \%$ of patients say it is easy to access care after hours. Our experience working with patients motivated us to host a 1-day engagement event to solicit patient feedback on how we could improve the typical medical visit. More than 350 patients volunteered, and we randomly selected 36 patient advisors representative of our practice demographics. Patient advisors were educated about our organisation and then worked together to make several practical recommendations that we have since implemented. ${ }^{13}$ We continue to engage patients in a variety of ways, from quick conversations in the waiting room to topic-specific focus groups, to indepth problem-solving with our Patient and Family Advisory Committee. Working with patients has helped shift our organisation to one that routinely values the patient perspective when designing programmes and services.

\section{Welcome criticism and accept imperfection}

'The data are wrong' is a common reaction when clinicians are presented with practice data. ${ }^{14}$ Sometimes the critics are right - the data are wrong or imperfect in some way. Our QI leaders have tried to welcome criticism, suppress our own defensive reactions, and have made changes to how we collect, analyse or present data based on staff feedback. For example, we added CIs to our data reporting, conducted a waiting room survey to understand if email responses to our patient survey were representative, ${ }^{7}$ and incorporated 
more data in our calculation of cancer screening. ${ }^{8}$ Sometimes we are just transparent about data limitations and acknowledge that a single measure only tells a piece of a larger story. We now respond to criticisms about data with an invitation to meet, review practice-level data and engage in dialogue about QI.

\section{Think in terms of ongoing improvement not time- limited projects}

Some experts have suggested that QI projects should be time-limited to maintain momentum. ${ }^{15}$ In our opinion, concerted efforts to enable change may be time-limited, but the commitment to monitor and sustain improvement in a core set of performance indicators should be ongoing. In our organisation, we monitor measures where we are performing well and select others for active improvement. Where relevant, data collection is integrated into the daily workflow of staff. Individual projects relate to the dashboard measures, ideally with a driver diagram to draw explicit connections. As Berwick ${ }^{16}$ wisely said, 'All improvement requires change, but not all change is improvement'. We have realised that change is often initiated by clinicians and managers not familiar with QI principles. Our QI team members emphasise the importance of understanding the problem before introducing a change and using data to understand the impact of change. We are striving towards an organisational culture where all staff answer the three questions from the Institute for Healthcare Improvement's Model for Improvement ${ }^{17}$ before pursuing a change idea.

\section{Integrate QI with management and operations}

Ongoing success has required the ongoing support of the department's executive team, and the leadership, time and expertise of a dedicated QI Programme Director who is involved in operational decision-making. In 2011, the department chief asked the new QI Programme Director to join the organisation's management team. Early on, the chief also ensured QI was a standing item on the medical staff meeting agenda with substantial dedicated time. QI initiatives are now embedded in the organisation's strategic plan. But there are ongoing tensions. We continue to have separate operations and quality committees. The former develops and oversees policies, procedures and day-to-day functioning. The latter monitors our dashboard measures and oversees improvement initiatives. But inevitably there is overlap. For example, improving access and patient-centredness is inextricably tied to management and operations. Having a separate QI committee though has helped us develop a cadre of staff across the organisation with time and skills to engage in improvement-staff who at first were relatively junior and have now developed leadership experience.

\section{CONCLUSION}

Clinician-led QI offers an opportunity to advance the inextricably linked goals of improving patient care and restoring meaning in work. We have offered insights from our own efforts in practice improvement over the last 7 years. Our organisation has developed a cadre of QI leaders, tracks a range of performance measures and has demonstrated sustained improvements in important areas of patient care. Success has required deep engagement with both patients and clinicians, a long-term vision, and requisite patience.

Correction notice This article has been corrected since it published Online First. One of the co-authors, Rajesh Girdhari's name was incorrectly displayed as Girdhari Rajesh.

Twitter@tara_kiran

Acknowledgements We would like to acknowledge the support and collective contributions of the St.Michael's Hospital Family Medicine Associates and the St. Michael's Hospital Academic

Family Health Team executive team, operations committee, quality steering committee, local quality improvement teams, and our electronic medical record associate, Lisa Miller.

Contributors TK drafted the manuscript and all authors critically reviewed it. All authors approved the final submitted version of the manuscript.

Funding Dr. Kiran is the Fidani Chair in Improvement and Innovation at the University of Toronto. She is supported as a Clinician Investigator by the Departments of Family and Community Medicine at St Michael's Hospital and the University of Toronto. She is also supported by Health Quality Ontario and the Canadian Institutes of Health Research as an Embedded Clinician Researcher. The authors have not declared a specific grant for this research fromany funding agency in the public, commercial or not-for-profit sectors.

Competing interests None declared.

Patient consent Not required.

Provenance and peer review Not commissioned; externally peer reviewed.

Data sharing statement No additional data are available.

Open access This is an open access article distributed in accordance with the Creative Commons Attribution Non Commercial (CC BY-NC 4.0) license, which permits others to distribute, remix, adapt, build upon this work noncommercially, and license their derivative works on different terms, provided the original work is properly cited, appropriate credit is given, any changes made indicated, and the use is noncommercial. See: http://creativecommons.org/licenses/by-nc/4.0

\section{REFERENCES}

1 Robin O, Schoen C. Chartpack: the commonwealth fund 2013 international health policy survey in eleven countries. Commonwealth Fund, 2013.

2 Schwenk TL. Physician well-being and the regenerative power of caring. JAMA 2018;319:1543-4.

3 Sinsky CA, Willard-Grace R, Schutzbank AM, et al. In search of joy in practice: a report of 23 high-functioning primary care practices. Ann Fam Med 2013;11:272-8.

4 Hutchison B, Glazier R. Ontario's primary care reforms have transformed the local care landscape, but a plan is needed for ongoing improvement. Health Aff 2013;32:695-703.

5 Rosser WW, Colwill JM, Kasperski J, et al. Patient-centered medical homes in Ontario. N Engl J Med 2010;362:e7.

6 Department of Family and Community Medicine and St, 2018. Michael's academic family health team. Available from: 
http://www.stmichaelshospital.com/programs/familypractice/ [Accessed 2 Jan 2018].

7 Slater M, Kiran T. Measuring the patient experience in primary care: comparing e-mail and waiting room survey delivery in a family health team. Can Fam Physician 2016;62:e740-8.

8 Feldman J, Davie S, Kiran T. Measuring and improving cervical, breast, and colorectal cancer screening rates in a multi-site urban practice in Toronto, Canada. BMJ Qual Improv Rep 2017;6:u213991.w5531.

9 Lofters AK, Schuler A, Slater M, et al. Using self-reported data on the social determinants of health in primary care to identify cancer screening disparities: opportunities and challenges. BMC Fam Pract 2017;18:31.

10 Institute for Healthcare Improvement, 2017. Third next available appointment. Available from: http://www.ihi.org/ resources/Pages/Measures/ThirdNextAvailableAppointment. aspx [Accessed 30 Jan 2018].

11 Lawton R, Taylor N, Clay-Williams R, et al. Positive deviance: a different approach to achieving patient safety. BMJ Qual Saf 2014;23:880-3.
12 Bate P, Robert G. Experience-based design: from redesigning the system around the patient to co-designing services with the patient. Qual Saf Health Care 2006;15:307-10.

13 Kiran T, Davie S, MacLeod P. Citizen engagement in primary care. Ann Fam Med 2018;16:175.

14 Brehaut JC, Colquhoun HL, Eva KW. Practice feedback interventions: 15 suggestions for optimizing effectiveness practice feedback interventions. Ann Intern Med 2016;164:435-41.

15 Institute for Healthcare Improvement, 2017. Concrete ideas to manage an improvement project. Available from: http:// www.ihi.org/education/WebTraining/Expeditions/2017-JunePractical_Strategies_for_Managing_Successful_Improvement_ Projects/Documents/Practical_Strategies_and_Ideas_for_ Managing_an_Improvement_Project_BRIEF.pdf [Accessed 2 Jan 2017].

16 Berwick DM. A primer on leading the improvement of systems. BMJ 1996;312:619-22.

17 Langley GJ, Moen RD, Nolan KM, et al. The improvement guide: a practical approach to enhancing organizational performance. John Wiley \& Sons, 2009. 